\title{
Outcomes of Primary Percutaneous Coronary Intervention at Shahid Gangalal National Heart Centre, Kathmandu, Nepal
}

Chandra Mani Adhikari,* Yadav Deo Bhatta, Rabi Malla, Arun Maskey, Rajib Rajbhandari, Shyam Raj Regmi, Ranjit Sharma, Subodh Kansakar, Himanshu Prasad Nepal, Nagma Shrestha, Rabindra Pandey, Dipankar Prajapati, Roshan Raut, Murari Dhungana, Dharma Nath Yadav, Binay kumar Rauniyar, Man Bahadur KC

Department of Cardiology, Shahid Gangalal National Heart Centre (SGNHC), Bansbari, Kathmandu, Nepal.

\section{Accepted on}

December $29^{\text {th }}, 2012$

DOI Name

10.3126/jaim.v2i1.7629

\section{Keywords}

Primary Percutaneous Coronary Intervention, Acute ST Elevation Myocardial Infarction, outcome.

\section{Citation}

Adhikari CM, Bhatta YD, Malla R, et al. Outcomes of Primary Percutaneous Coronary Intervention at Shahid Gangalal National Heart Centre, Kathmandu, Nepal. Journal of Advances in Internal Medicine 2013;02(01):6-9.

\begin{abstract}
Background and Aims- Reperfusion therapy is indicated for patient with acute ST Elevation Myocardial Infarction. Several randomized trials and meta-analyses have shown that Primary Percutaneous Coronary Intervention is better than thrombolysis. Our aim was to determine the outcomes of Primary Percutaneous Coronary Intervention in Shahid Gangalal National Heart Centre, Nepal.

Methods- Medical records of 212 Primary Percutaneous Coronary Intervention from March 2007 to March 2012 were retrospectively reviewed. The primary end point was in-hospital mortality and secondary end points were 30 day mortality and long term mortality.
\end{abstract}

Results- In the patients presenting to emergency with acute ST elevation myocardial infarction, inferior wall Myocardial Infarction 64 (30\%) was the most common. Single vessel disease 168 (79\%) predominated in emergency coronary angiogram. In majority of the patients Right Coronary Artery 103 (48.7\%) was the culprit vessel. Cardiogenic shock was present in 28 (13.2\%) patients. There were 11 deaths (39.2\%) in cardiogenic shock group where as only 5 deaths (2.7\%) among 184 non cardiogenic shock patients, resulting in in hospital mortality rate of $7.5 \%$.

Among the 196 patients who were successfully discharged from the hospital, 21 patients lost to follow up. There was one death reported within a month, non within three months and four within a year post discharge from the hospital.

Conclusions- The result of this study is comparable to the findings elsewhere in the world. Primary Percutaneous Coronary Intervention should be the treatment of choice in treating acute myocardial infarction where the facilities and the expertise are available.

\section{INTRODUCTION}

Acute ST segment Elevation Myocardial Infarction (STEMI) is caused by the rupture or erosion of an atherosclerotic plaque of a coronary artery, initiating intra luminal thrombosis resulting in partial or complete occlusion. ${ }^{1,2}$ Reperfusion therapy (mechanical or pharmacological) is indicated for the patients with acute STEMI if they arrive within the ideal time. The prognosis is better and has improved over the years; inhospital mortality rates fell from $11.2 \%$ in 1990 to $9.4 \%$ in $1999 .{ }^{3}$ the decline in mortality ${ }^{4}$ is due to use of thrombolytic agents and advent of Primary Percutaneous Coronary Intervention (PPCI). National Registry of Myocardial Infarction (NRMI) shows that the rate of in-hospital mortality was $5.7 \%$ among those who received reperfusion therapy, and $14.8 \%$ among those who were eligible for but did not receive such therapy. ${ }^{5}$ When compared to conservative management, fibrinolytic therapy improved left ventricular systolic function and survival in patients with STEMI. In a pooled analysis of nine large trials, the rate of death within 35 days was 9.6\% among patients who received fibrinolytic therapy and $11.5 \%$ among control subjects. ${ }^{6}$ However, fibrinolytic therapy is contraindicated in some patients $(27 \% \text { in one report })^{7}$ and is not successful in some. ${ }^{8,9}$ In about a quarter of those who have received fibrinolytic therapy have reocclusion of the infarct-related artery within three months after the myocardial infarction, with a resultant reinfarction. ${ }^{10}$ These limitations are minimized with the use of $\mathrm{PPCl}$. Several randomized trials and meta-analyses have shown that $\mathrm{PPCl}$ is better than thrombolysis not only in terms of death at 4 to 6 weeks after treatment ( $7 \%$ vs. $9 \%),{ }^{11}$ but also in rate of reinfarction, and stroke. ${ }^{12}$ Therefore PPCI is the preferred treatment for STEMI and is effective in opening the infarct-related artery. ${ }^{13,14}$

The $\mathrm{PPCl}$ is an emergent interventional procedure in which balloon dilatation (with or without stenting) of an infarct related coronary artery is done. Coronary angiography is performed to identify the site of thrombotic occlusion. Then a guidewire is advanced through the occlusion over which a balloon catheter (with or without a stent) is passed and positioned at the site of the occlusion and inflated, opening the occlusion and restoring the antegrade flow. The PPCI restores normal flow in the previously occluded artery in more than $90 \%$ of patients, ${ }^{15}$ whereas thrombolysis does so in only 50 to $60 \%{ }^{16}$ as shown by post thrombolysis angiogram.

\footnotetext{
* Corresponding author

Chandra Mani Adhikari

Shahid Gangalal National Heart Centre,

Bansbari, Kathmandu, Nepal

Email: topjhap@hotmail.com
} 
$\mathrm{PPCl}$ is preferred to thrombolysis if a skilled and experienced interventional cardiologist and a properly equipped catheterization laboratory is available and if the procedure can be performed preferably within 90 minutes after first medical contact with the patient. ${ }^{17}$ Studies from India, ${ }^{18}$ Bangladesh, ${ }^{19}$ and Pakistan ${ }^{20}$ concluded that primary angioplasty is safe and effective in the developing countries in South Asian region.

\section{METHODS}

It is a retrospective, single centre study, performed at Shahid Gangalal National Heart Centre, Bansbari, Kathmandu, Nepal. Medical records of all STEMI patients who underwent successful PPCI March 2007 to March 2012 were retrospectively reviewed. Performa was designed to collect patient information which included; age, gender, diabetes, dyslipidemia (based on Lipid profile after admission), hypertension based on history and on blood pressure measurement), smoking, left ventricular function (based on echocardiography), presence of cardiogenic shock (defined as a systolic blood pressure of $<90 \mathrm{mmHg}$ at the time of arrival). Angiographic and procedural details (culprit vessel, number of diseased vessels, and use of stents) were also collected. Nursing Charts were reviewed for blood pressure at the time of arrival and the time of the procedure.

The primary end point was in-hospital mortality and secondary end points included 30 day mortality from discharge and long-term mortality.

Cardiovascular risk factors were defined according to American College of Cardiology Key Data Elements and Definitions for Measuring the Clinical Management and Outcomes of Patients with Acute Coronary Syndrome.

1. Smoking: History confirming cigarette smoking (regularly smokes one or more cigarettes per day)

2. Dyslipidemia: History of Dyslipidemia diagnosed and/or treated by physician or meets the criteria of National Cholesterol Education Program:

a. Total cholesterol (TC) greater than $5.18 \mathrm{mmol} / \mathrm{l}$; or

b. Low-density lipoprotein (LDL) greater than or equal to $3.37 \mathrm{mmol} / \mathrm{L}$; or

c. High-density lipoprotein (HDL) less than $1.04 \mathrm{mmol} / \mathrm{L}$.

3. Hypertension (HTN): defined as blood pressure $\geq 140 / 90$ $\mathrm{mmHg}$ or on treatment.

4. Diabetes (DM): defined as a fasting glucose $\geq 7.1 \mathrm{mmol} / \mathrm{L} 2$ hour of post prandial glucose $\geq 11.1 \mathrm{mmol} / \mathrm{L}$ or on treatment.

Follow up was conducted via telephone and through Outpatient visits. All the variables were entered into the Statistical Package for Social Sciences software, version 14 (SPSS Inc) for data analysis. Descriptive statistics were computed and presented as means and standard deviations for continuous variables like age, Left Ventricular Ejection Fraction (LVEF), categorical variables were reported in percentages for the gender, hypertension, diabetes mellitus, dyslipidemia, cardiogenic shock, left ventricular failure, multi vessel disease, in-hospital mortality, in-hospital and 30-days Survival Outcome.

\section{RESULTS}

A total of 212 patients were included in this study. Table-1 shows the demographic and clinical characteristics as well as outcomes of the studied cohort. The mean age was $56.9 \pm 12.4$ years. There were $173(82 \%)$ males and 39 (18\%) females. Out of $212 \mathrm{PPCl}$ patients 127 (60\%) were smoker, 63 (30\%) patients were diabetic, 110 (51\%) hypertensive and $130(61 \%)$ had dyslipidemia. Table- 2 shows the angiographic and procedural details of the patients undergoing primary $\mathrm{PCl}$. In coronary angiogram triple vessel disease (defined as > 50\% stenosis in other two vessels other than the culprit vessel), in $13(6 \%)$, double vessel disease 30 (14\%), single vessel disease in 168 (79\%) and left main with double vessel disease was present in one patient. Based on the emergency ECG Inferior wall myocardial infarction (MI) 64 (30\%) was the common cause for $\mathrm{PPCl}$, followed by Anterior wall MI 60 (28\%), Extensive anterior wall MI 32 (15\%), Inferior wall MI with RV extension 29 (14\%), Infero posterior wall MI 24 (12\%), Posterior wall MI 2 (0.9\%) and Lateral wall MI 1 (0.4\%). In most patient 103 (48.7\%) Right Coronary Artery (RCA) was the culprit vessel followed by Left Anterior Descending Artery (LAD) 92 (43.6\%), Left Circumflex (LCX) $16(7.3 \%)$ and venous graft in $1(0.4 \%)$ patient.

Table 1. Baseline Demographic and Clinical characteristics:

\begin{tabular}{|c|c|c|}
\hline Demographic and Clinical characteristics & & $N=212$ (\%) \\
\hline Mean Age & \multicolumn{2}{|c|}{$56.9 \pm 12.4$ years } \\
\hline Age $>75$ years & 21 & (9.9) \\
\hline Male/Female & 173 & (82\%) / 39 (18\%) \\
\hline \multicolumn{3}{|l|}{ Past Medical History } \\
\hline Hypertension & 110 & (51) \\
\hline Diabetes & 63 & (30) \\
\hline Smoker & 127 & (60) \\
\hline Dyslipidemia & 130 & (61) \\
\hline \multicolumn{3}{|l|}{ Admission Characteristics } \\
\hline Cardiogenic Shock & 28 & $(13.2)$ \\
\hline Anterior wall $\mathrm{MI}$ & 60 & (28) \\
\hline Extensive Anterior wall MI & 32 & (15) \\
\hline Inferior wall MI & 64 & (30) \\
\hline Inferior wall MI with RV extension & 29 & (14) \\
\hline Infero posterior wall MI & 24 & (12) \\
\hline Posterior wall MI & 2 & (0.9) \\
\hline Lateral wall MI & 1 & $(0.4)$ \\
\hline \multicolumn{3}{|l|}{ In hospital events } \\
\hline In hospital mortality & 16 & (7.5) \\
\hline In hospital mortality in patient with shock & $11 / 28$ & (39.2) \\
\hline In hospital mortality in patient without shock & $5 / 184$ & (2.7) \\
\hline 30 day mortality & 1 & \\
\hline 1 year mortality & 4 & \\
\hline
\end{tabular}

Stents were deployed in 201 (94.5\%) patients, 11 (5.5\%) patient were treated without stent with thrombo suction and Plain Balloon Angioplasty (POBA). More than one stent were used in $18(8 \%)$ of the patients, two Bare Metal Stents (BMS) in 13 (6\%), two Drug Eluting Stents (DES) in four (1.8\%), a single DES and a single BMS in four (0.4\%).In 115 patients, 128 BMS were used, where as 91 DES were used in 88 patients.

Among the 28 patient who presented in cardiogenic shock, 17 patients presented with Inferior wall MI with RV extension, 3 with extensive ant wall $\mathrm{MI}, 3$ with anterior wall myocardial infarction and 3 with infero posterior wall MI. 
Table 2. Angiographic and procedural characteristics

\begin{tabular}{lll}
\hline Angiographic and procedural characteristics & \multicolumn{2}{c}{$\mathbf{N = 2 1 2}(\%)$} \\
\hline Culprit vessel: & 103 & $(48.7)$ \\
$\quad$ Right Coronary Artery & 92 & $(43.6)$ \\
$\quad$ Left Anterior Descending & 16 & $(7.3)$ \\
$\quad$ Left circumflex & 1 & $(0.4$ \\
$\quad$ Venous graft & 168 & $(79.3)$ \\
Single Vessel CAD & 44 & $(20.7)$ \\
Multivessel CAD & 1 & $(0.4)$ \\
Left Main Disease & 201 & $(94.5)$ \\
Use of Stent & 11 & $(5.5)$ \\
POBA and thrombosuction & 18 & $(8)$ \\
More than one stent & $92(43.4) / 115(54.2)$ \\
Drug eluting stent/Bare Metal stent & $124(58.5) / 88(41.5)$ \\
PPCl during working hours / Off hour & \multicolumn{2}{c}{} \\
\hline
\end{tabular}

In hospital mortality was 16 (7.5\%). Among the deaths, eight were male and eight female, nine were less than 75 years old, and seven aged more than 75 years. Shock was present in 11 patients, Inferior wall MI with RV extension was present in six patient followed by extensive anterior three, anterior wall $\mathrm{MI}$ in three, inferior wall $\mathrm{MI}$ two and inferior posterior wall MI. Among the deaths 11 had SVD and five have DVD. Among the mortality eight patients underwent PPCI in RCA, In LAD six and LCX in two patients. Among the death nine patients underwent $\mathrm{PPCl}$ during routine working hours (9 AM - 5 PM), 7 patients during off hours (5PM - 9AM). Among the 196 patients who were successfully discharged after PPCI, 175 patients could be contacted via phone or Out Patient (OPD) visits, where as 21 patient lost to follow up. There was a single death within 30 days after discharge and no mortality within three month of discharge. There were four deaths during one year of follow up.

\section{DISCUSSION}

The PPCI has potential benefits of specific and confirmed recanalization of the culprit vessel as well as knowledge of the detailed coronary anatomy. The possible risks associated with primary $\mathrm{PCl}$ includes bleeding, procedure related immediate complications and radiographic contrastrelated acute renal failure. ${ }^{21}$

This study shows most common culprit vessel is Right coronary artery (48\%) followed by left anterior descending artery (LAD) (43.5\%) and left circumflex artery (LCX) (8.4\%). A study in Pakistan showed LAD was the most commonly identified culprit vessel $58(55.7 \%)$ followed by RCA and LCX $36(34.6 \%)$ and $10(9.6 \%)$ respectively. ${ }^{20}$ In the same type of study in Bangladesh PPCI to RCA in 50\% was the common cause for PPCI followed by LAD $43.3 \%$, and LCX $6.7 \% .{ }^{19}$

Our study shows an excellent overall in-hospital survival rate (92.5\%) which is comparable to Pakistan $(94.2 \%)^{20}$ and Bangladesh (93.3\%). ${ }^{19}$ Five patient out of 184 (2.7\%) patients without cardiogenic shock died which is comparable to international data which shows in-hospital mortality of $5.2 \%$ in Second National Registry of Myocardial Infarction (NRMI2) ${ }^{22}$ and $3 \%$ in ASSENT 4 trial. ${ }^{23}$

In our study 28 patients had cardiogenic shock out of them 11 died (39.2\%) which is again comparable to international data which shows higher mortality in patients with cardiogenic shock i.e. $45 \%$ in Pakistan, ${ }^{20}$ $32 \%$ in NRMI $2,{ }^{22} 46.4 \%$ in SHOCK registry ${ }^{24}$ and $59.1 \%$ in American College of Cardiology-National Cardiovascular Data Registry (ACC-NCDR). ${ }^{25}$ A study from India by Reddy et $\mathrm{a}^{18}{ }^{18}$ showed an in-hospital mortality of $2.2 \%$ in non-cardiogenic shock group, similar outcomes were observed in a JCIA certified local study with mortality of $43.9 \%$ and $2.1 \%$ in patients undergoing primary angioplasty for STEMI with and without cardiogenic shock respectively. ${ }^{26}$

In our study mortality in women is quite high $20.5 \%$ vs. $4.6 \%$ in men. Mortality is high in patient more than 75 compared to less than 75 years.33.3\% vs. $4.7 \%$. Based upon the culprit vessel PPCI in LCX (12.7\%) had higher mortality rate compared to RCA (7.7\%) and LAD (6.5\%). Mortality rate is quite similar between the $\mathrm{PPCl}$ during off hour and the usual working hour $(7.9 \%$ vs. $7.2 \%)$.There was few procedure related complications, ten patients had hematoma at puncture site, three developed transient ischaemic attack and three developed Contrast Induced Nephropathy out of which one required dialysis.

This study is comparable to international standards in improving acute and long term mortality. PPCI is the treatment of choice for acute ST elevation $\mathrm{MI}$ and should be strongly recommended when indicated.

\section{CONCLUSION}

The study findings suggest that favorable outcomes, matching the international standard can be achieved in developing countries like Nepal with PPCI in the management of acute STEMI. It is not only safe but also improves the in-hospital and 30-days survival outcome. PPCI as a preferred method of reperfusion strategy needs to be practiced more even in developing countries when the facilities are available.

\section{REFERENCES}

1. Falk E. Plaque rupture with severe pre-existing stenosis precipitating coronary thrombosis: characteristics of coronary atherosclerotic plaques underlying fatal occlusive thrombi. $\mathrm{Br}$ Heart J 1983;50:127-34.

2. Davies MJ, Thomas A. Thrombosis and acute coronary-artery lesions in sudden cardiac ischemic death. $N$ Engl J Med 1984;310:1137-40.

3. Rogers WJ, Canto JG, Lambrew CT, et al. Temporal trends in the treatment of over 1.5 million patients with myocardial infarction in the U.S. from 1990 through 1999: the National
Registry of Myocardial Infarction 1, 2 and 3. J Am Coll Cardiol 2000;36:2056-63.

4. Furman MI, Dauerman HL, Goldberg RJ, et al. Twenty-two year (1975 to 1997) trends in the incidence, in-hospital and long-term case fatality rates from initial Q-wave and non-Q-wave myocardial infarction: a multi-hospital, community-wide perspective. J Am Coll Cardiol 2001;37:1571-80.

5. Gibson CM. NRMI and current treatment patterns for ST-elevation myocardial infarction. Am Heart J 2004;148:Suppl:S29-S33.

6. Fibrinolytic Therapy Trialists' (FTT) Collaborative Group. Indications for fibrinolytic therapy in suspected acute myocardial 
infarction: collaborative overview of early mortality and major morbidity results from all randomised trials of more than 1000 patients. Lancet 1994;343:311-22.

7. Juliard JM, Himbert D, Golmard JL, et al. Can we provide reperfusion therapy to all unselected patients admitted with acute myocardial infarction? J Am Coll Cardiol 1997;30:157-64.

8. The GUSTO Angiographic Investigators. The effects of tissue plasminogen activator, streptokinase, or both on coronary-artery patency, ventricular function, and survival after acute myocardial infarction. N Eng/ J Med 1993;329:1615-22.

9. Anderson JL, Karagounis LA, Becker LC, et al. TIMI perfusion grade 3 but not grade 2 results in improved outcome after thrombolysis for myocardial infarction: ventriculographic, enzymatic, and electrocardiographic evidence from the TEAM-3 Study. Circulation 1993;87:1829-39.

10. Gibson CM, Karha J, Murphy SA, et al. Early and long-term clinical outcomes associated with reinfarction following fibrinolytic administration in the Thrombolysis in Myocardial Infarction trials. J Am Coll Cardiol 2003;42:7-16.

11. Keeley EC, Boura JA, Grines CL. Primary angioplasty versus intravenous thrombolytic therapy for acute myocardial infarction: a quantitative review of 23 randomised trials. Lancet 2003;361:13-20.

12. De Luca G, Suryapranata H, Marino P. Reperfusion strategies in acute ST-elevation myocardial infarction: an overview of current status. Prog Cardiovasc Dis 2008;50:352-82.

13. Zijlstra F, Hoorntje JC, de Boer MJ, et al. Long-term benefit of primary angioplasty as compared with thrombolytic therapy for acute myocardial infarction. N Eng/ J Med 1999;341:1413-9.

14. Keeley EC, Boura JA, Grines CL. Primary angioplasty versus intravenous thrombolytic therapy for acute myocardial infarction: a quantitative review of 23 randomised trials. Lancet 2003;361:13-20.

15. Grines $\mathrm{CL}$, Cox DA, Stone GW, et al. Coronary angioplasty with or without stent implantation for acute myocardial infarction. N Engl J Med 1999;341:1949-56.

16. Keeley EC, Hillis DL. Primary PCI for Myocardial Infarction with STSegment Elevation. N Engl I Med 2007;356:47-54.

17. Cannon CP. Evolving management of ST-segment elevation myocardial infarction: update on recent data. Am J Cardiol
2006;98:10Q-210

18. Reddy NK, Raju PR, Kapoor S, et al. Prospective observational study of primary angioplasty of the infarct-related artery for acute myocardial infarction. Indian Heart J 1999;51:167-72.

19. Reza AQM, Islam AHMW, Munwar S, et al. Study on Primary Percutaneous Coronary Intervention (PCl) in Patient with Acute Myocardial Infarction: In-Hospital and 30-days Survival Outcome. Cardiovascular Journal 2010;2:212-7.

20. Shaikh AH, Siddiqui MS, Hanif B, et al. Outcomes of primary Percutaneous Coronary Intervention (PCI) in a Tertiary Care Cardiac Centre. JPMA 59:426;2009.

21. Aversano T, Aversano LT, Passamani E, et al. Thrombolytic therapy vs primary percutaneous coronary intervention for myocardial infarction in patients presenting to hospitals without on-site cardiac surgery: a randomized controlled trial. JAMA 2002;287:1943-51.

22. Tiefenbrunn AJ, Chandra NC, French WJ, et al. Clinical experience with primary percutaneous transluminal coronary angioplasty compared with alteplase (recombinant tissue-type plasminogen activator) in patients with acute myocardial infarction: a report from the Second National Registry of Myocardial Infarction (NRMI-2). J Am Coll Cardiol 1998;31:1240-5.

23. Van de Werf on behalf of the Assent-4 PCI Investigators, Primary versus tenecteplase-facilitated percutaneous coronary intervention in patients with ST-segment elevation acute myocardial infarction (ASSENT-4 PCI): randomised trial. Lancet 2006;367:569-78.

24. Webb JG, Sanborn TA, Sleeper LA, et al. Percutaneous coronary intervention for cardiogenic shock in the SHOCK Trial Registry. Am Heart J 2001;141:964-70.

25. Klein LW, Shaw RE, Krone RJ, et al. Mortality after emergent percutaneous coronary intervention in cardiogenic shock secondary to acute myocardial infarction and usefulness of a mortality prediction model. Am J Cardiol 2005;96:35-41.

26. Jafary FH, Ahmed H, Kiani J. Outcomes of primary percutaneous coronary intervention at a joint commission international accredited hospital in a developing country -can good results, possibly similar to the west, be achieved? I Invasive Cardiol 2007;19:417-23. 